\title{
Influence of Cultural Value System and Home on Child-Rearing Practices in the Contemporary Nigerian Society
}

\author{
Mary Basil Nwoke \\ Department of Psychology, University of Nigeria, Nsukka, Nigeria \\ Email: mbnwokeddl@yahoo.com
}

Received August $24^{\text {th }}, 2012$; revised September $27^{\text {th }}, 2012$; accepted October $10^{\text {th }}, 2012$

\begin{abstract}
The study investigated influence of cultural values and home on child-rearing practices in Nigeria. Value systems are embedded in the culture of people. Culture is a set of shared values, attributes, customs and physical objects that are maintained by people in a specific setting. Cross-sectional design and qualitative technique was employed to obtain information from participants. Participants were sixteen adults ( 8 men, 8 women) from four ethnic groups: Igbo, Ogoni, Tiv and Yala. Findings showed that different cultures have their value systems and these values were inculcated to generations of the members through childrearing practices. At the age of 5 years, each culture initiates the young ones into her way of life, such as the behavioural pattern expected of the child at the home or farm. Yala Queen dancing/greeting pattern, Ogonis and her yaa/koo rites of passage into adulthood; Tivs and the sacredness of her land; Igbos and their importance of kolanut. These values are transmitted to generations of human beings through childrearing practices. The home is the miniature society which nurtures value system.
\end{abstract}

Keywords: Child-Rearing; Culture; Value System; Society

\section{Introduction}

Etymologically, value system and societal norms are embedded in the culture of the people. Culture is a set of shared values, attributes, customs and physical objects that are maintained by people in a specific setting as part of a design for living one's daily life as well as assumptions and everything from clothing, dwellings, technologies and works of art that a group of people have developed over the years, as a design for trying to structure their life together. These values and norms are transmitted to generations of human beings through childrearing practices in the homes. Every home is a miniature society, contains all the societal value systems and serves as nursery that nurtures all cultural values (Berger \& Thompson, 1998). Looking closely at various designs for living, it becomes clear that cultural value system and norm guide human development in a multitude of interrelated ways. For instance, Levine (1980, 1989) observed that children are an economic asset because they can contribute to the family's farming and later form a strong family unit to preserve the land and to care for ageing parents. Thus every infant who survived to childhood and beyond benefits the entire family. Levine noted that in most of those communities, there was poor nutrition and poor medical care, leading to high infant mortality rates. The priority attention of child rearing was designed to maximize survival of the infants and therefore emphasized family cooperation. The typical home features include: intensive physical care of infants, feeding on demand, immediate response to crying, close body contact, keeping the child close at night, and constant care by siblings and other relatives as well as by the mother. All these measures are values to protect the fragile human infant from an early death and work to establish such values as the interdependence of family members.

By contrast, Levine (1989) observed that, American middle- class parents may not have much concern about infant mortality, instead ensuring their children's future success in technological and urbanized society takes priority attention in their childrearing practices. They focus their child rearing efforts on fostering cognitive growth and emotional independence. Hence typical American middle-class parents engage their infants in activities that provide cognitive and social stimulation, talk to their infants more than touch them, put them to sleep themselves in their own cribs in their rooms, and often ignore their crying so as not to spoil them. It is not surprising these contrasting parental strategies in child-rearing practices produce children with quite different capacities, goals and expectations. However, in both cases the children became relatively wellprepared for the cultural value system in which they were raised. Home value system and cultural norms involve the behaviour patterns, beliefs and all other products of a particular group of people which are passed on from generation to generation (Phinney \& Alipura, 1990). There are various ways in which home values and cultural norms, which are embedded in the culture could have influence on the personality of an individual and modes of adjustment in life. Sechrest and Wallace (1967) observed that culture and personality are two ways of looking at the same phenomenon. Individual's personality is the end product of an interaction between biological and experiential factors and experiential factors are in part culturally determined. Sechrest and Wallace (1967) hold firm that the most evident source of value system influence on personality is by way of child-rearing orientations that are culturally conditioned. Haralambos and Heald (1980) observed that "for all intents and purposes a new human baby is helpless. Not only is it physically dependent on older members of the species, but it also lacks the behaviour pattern necessary for living in human society. It relies primarily on certain biological drives such as hunger and the charity of its elders to satisfy those drives. In order 
to survive, the human infant must learn the skills, knowledge and accepted ways of behaving of the society into which it is born" (p. 3). Kluckhohn (1951 as in Haralambos \& Healed, 1980) posited that culture is a design for living held by members of a particular society. In order for a society to operate effectively, this design must be shared by its members. So in all, cultural value systems are transmitted to generations of offspring through child-rearing practices in the homes.

Analyzing the cultural value system in Africa, Dukor (2010) observed that every ethnic group has a set of social value system in her cultural environment, such values as poetry, architecture, food and work habit, farming and fetching water and many others; such are transmitted to generations of humans through child-rearing practices in the homes. Dukor (2010) indicated that when cultural values are enacted and assimilated, they become a form of law or guide to the group (like Thomas Paine right of man, the American declaration of independence and the United Nation Charter on human rights). Dukor (2010) categorized cultural values into moral normative values and non moral normative values. He indicated that the moral normative values consist in what he called ethical or axiological values, while aesthetic and artistic values make up the non moral normative values in African philosophy. Dukor (2010) observed that the issue of prepositions and entailments of African cultural ethical values arise because these values are embedded in African folklore, proverbs and wise-sayings on one hand and on the other hand there are prepositions within the kinship-extended family ties and communalistic system. Dukor (2010) attested that an ethical or moral normative cultural value can be extracted prepositionally from a set of proverbs or folklore or from the African communication philosophy, for example, in Nigeria, no police is set to enforce moral values in Igbo society, since the spirit of moral responsibility and communalism or kinship takes care of deviances. For instance (Dukor, 2010) cited the Igbo proverb that "when a man dances badly in public it is his brothers (brethren) that get the itching brow" meaning that unruly behaviour is a disgrace not only to oneself, but to his entire family and community. He put his "Theistic Humanism model" into two groups A \& B. In group "A" is the community values. In the community values are the kinship, extended family, communitarianism, social values and ethical issues. In group "B" is the aesthetical values. In the aesthetical values are the food \& work habit, agriculture \& architectural values, music, artistic and celebration of life values. All these philosophical ways of life, wise-sayings, folklore, belief system, prescriptions and postscriptions and other invaluable salient values in the family level, community level or society at large, as enunciated by Dukor, is inculcated to generations of human beings through child-rearing practices in the homes.

Nigeria with her diversified cultural background, value systems and with numerous ethnic groups, each ethnic group has her peculiar way of child-rearing practices through which the group's value and norms are transmitted to generations of offspring. The home is the custodian of cultural value system. For instance, the home initiates the child into her value system and the cultural norms such as dressing pattern, greeting pattern, eating ethics, cooking methods, language, dance, like acrobatic displays, masquerade, morals, habits and gender character wise. The males are trained on how to be dominant, defensive, and strong among other masculine qualities. The girl child is trained in feminine qualities of submissiveness, gentleness, quiet, humble, caring, which calls for mothering. The girl child is taught domestic chores and how to take care of the home. The values people adhere to often affect their cognition, their learning, understanding, thinking, imagining, reasoning, and creative processes. Chukwuaguh, (1998) observed that "the hidden aspects of a culture which comprises beliefs, ideals, values, assumptions and modes of thought which members of a group adhere to, govern not only the behaviour of the group, but also their cognitive world view in a profound manner" (p. 70). For example among the Igbo of Nigeria, the presentation and breaking of kola nut is a value system that almost every Igbo speaking group held prominent. In Igbo land, kola nut is not shown to females whatever their age and the language of the immediate locality where the kola was presented is always used in praying while breaking it. This value system is transmitted to generations of Igbo people through child-rearing, (Nwoke, 2004; Uzoka, 2010).

In another view, Sechrest and Wallace (1967) observed that value system and heritage are deeply imbedded, that the culturally determined way of doing things and the look on life seems natural and right in comparison with other peoples. They saw that there are various ways in which cultural value system and home might have impact on the personality of the individual human being and his/her modes of adjustment. Every culture provides both prescriptions and postscriptions for behaviours, systems of reward and sanctions are very often specified and they are inculcated to the offspring through rearing practices. Thus certain forms of behaviours are prescribed and even rewarded while other forms may be forbidden and punished. Nwoke (2004) observed that in some part of Igbo land, the eating of new yam is highly celebrated. The contravention of this value system by any member of this group attracts heavy sanction because such a person has defiled the cultural value system no matter the influence of modernity or Christianity; while in some other parts, new yam is eaten like any other food. Yala in Ogoja of Cross-River State has similar value for their new yam in the sense that every Yala son or daughter goes home for the celebration. Of course, different cultures accord yam products with varieties of celebration.

\section{Review of Related Literature}

Evaluating the impact of cultural values and norms on the lives of humanity, Argyle (1970), Sechrest and Wallace (1967) observed that culture provides its members with a cognitive structure from within which they will review and try to make sense out of, through their experiences. Through the value system, cognitive and linguistic structures suitable to the problems that must be dealt with by persons living in that culture are provided and such values are transmitted to the young ones through child-rearing in the homes. One of the most intriguing and influential hypotheses concerning value system was advanced by Whorf (1956 as in Sechrest and Wallace, 1967) who postulated that the nature and structure of the language determines cognitions which are possible in any culture; and are transmitted to offspring through child-rearing methods in the homes. For example in Igbo culture, the word "akwa" has many meanings àkwà = bed; àkwá = egg; àkwa = bridge; àkwā = clothes; àkwa = cry. However, the meaning "àkwa" conveys depends on the pronunciation of the last article à; (or the semantic). Among the Effiks of Nigeria, the word obong could mean mosquito or chieftaincy depending on the pronunciation and it is transmitted to generations of children. It was also re- 
ported by Sechrest and Wallace (1967) that the Hununoo tribe of the Philippines distinguished 92 varieties of values of what is called "rice" in English. In such tribe, it may be possible for homes (families) to inculcate the 92 varieties of values attached to the word "rice" to their children through rearing practices.

In a study by Evans-Pritchard (1940), the Nuer tribe along the upper Nile in Africa, are remarkable of the value attached to cattle in almost every aspect of their lives. The Nuer use the milk from cows, they routinely puncture blood veins in the neck to drain blood which they use for food, they utilize cow dung for fuel, "cement" and hair dressing. They eat the meat and use the hides from slaughtered animals. Among the Nuer, a man takes his name from his favourite oxen and spends a major part of his time in providing for the welfare and safety of his cattle. The Nuer-cow-value system is genuinely symbiotic. They use a thousand and one terms to distinguish their cattle. This is how thousand and one values held by cultures are transmitted to generations of human beings through the home socialization in the child-rearing processes. The children reared in Nuer tribe may not know any other language than that of human-cattle-relationship, because they will be initiated into cattle rearing early in life; like the Fulani in Nigeria who initiate their children to their street lifestyle of cattle rearing as early as the age of five. This value of following cattle up and down hills and streets which is transmitted to offspring through child-rearing might make it quite impossible for most Fulani children to understand any other value language than that of cattle-rearing and following cattle. Hence Wegh (1994) observed that no human child can socially or cognitively develop beyond the type of life or value system prevalent in his/her culture. Thus, whatever the value system, the home environment, social environment or cultural environment bequeaths the growing child with, it is what he/she builds his/her own personality on.

Herskovits (1955) observed that all over the world, and across period of time, very diverse concepts of value system have evolved. For instance, homicide, suicide, cannibalism, homosexuality and incest have all apparently been regarded as permissible and may even be desirable behaviours in some societies while they are taboos in some other societies. For example, in some part of America they are acceptable, in some part of Africa, they are taboos. In a similar vein, Herskovits (1955), Smith, Sarason \& Sarason, (1986) Santrock (2006) observe that hallucination which is regarded as a symptom of serious mental disorder is sought rather than feared or avoided by some tribes. For example the Plains Indians of North America often sought hallucinatory experiences as a form of divine guidance or as a sign of initiation. These authors affirmed that other symptoms such as delusion of being possessed by spirits and experiencing of dissociative trance states, have not only been accepted but in some cultures opened up opportunities for their victims to serve as a shaman or priest. So while children from Plains Indian of North America may be able to interpret delusion and hallucinatory experiences as a "divine call", children from some other cultures like Nigeria, may see such experiences as possessed or sick. Indeed, it may be obvious that such value system may be foreign or abnormal and could be seen as the onset of pathological cases in some cultures like Nigeria. This value system is inculcated to generations of offspring through child-rearing practices.

Talking about cultural value system, Nwideeduh (1998) disclosed that the Ogonis of Rivers State are culturally matrilineal and this is inherited as well as inculcated. The Ogonis practice cultural rite of passage or initiation into manhood or womanhood, which they called "yaa" for males and "koo" for females, and this cultural value system is prominent that an Ogoni man is ready to invest a treasure in the initiation ceremony of "yaa" and "koo" of his children than to invest any penny on education for the children. Nwideeduh (1998) emphasized that to change an Ogoni man's mind from "yaa" and "koo" initiation cultural value system would mean turning the culture upside down or to obliterate Ogoni culture from the universe. Culturally, every group of people value their land, but, Downess (1933; Wegh 1994; Jov, 2001; Nwoke, 2004) indicated that the Tiv people do not conceive their land simply as a tract of the earth on which they live. It is the land of their fathers. It is "sacred" land. That is why Tiv always fights against any encroachment made on Tiv land. Tiv cultural value system is often portrayed in their attire. Bohannan (1965) referring to the unique characteristics of the Tiv, stated that the Tiv do not present the difficulty prevalent among Africans in identifying the ethnic group. Bohannan (1965) added: "the Tiv are of an independent turn of mind and are almost surely the most ethnocentric people in the world" (p. 516). This assertion is because the Tiv were strongly hostile to any external force that would infiltrate their cultural heritage. These values are inculcated to generations of Tiv children through child-rearing practices.

On how great an influence of the home value system inculcated to the child through rearing practices; was expressed by an anonymous writer (in Hurlock, 1978) in the following ways:

- If a child lives in criticism, he learns to condemn.

- If the child lives with hostility, he/she leans to fight.

- If the child lives with fear, he/she learns to be apprehensive.

- If the child lives with pity, he/she learns to feel sorry for self and others.

- If the child lives with tolerance, he/she learns to be patient.

- If the child lives with jealousy, he/she learns to feel guilty.

- If the child lives with ridicule, he/she learns to be shy.

- If the child lives with shame, he/she learns to be ashamed of himself/herself.

- If he/she lives with encouragement, he/she learns to be confident.

- If he/she lives with praise, he/she learns to love.

- If he/she lives with acceptance, he/she learns to like himself/herself.

- If the child lives with approval, he/she leans to have a goal.

- If the child lives with recognition, he/she learns to value justice.

- If the child lives with honesty, he/she learns to value truth.

- If the child lives with security, he/she learns to have faith in himself/herself and others.

In line with the assertion in Hurlock (1978), value system is an inextricable cultural or home value which the individual is born into, and is innately fixated in the behavioural pattern of such individual or group of individuals. The value system of any group affects their lifestyle and such is inculcated to the children. For example there some religious sects whose means of livelihood is beggary, they inculcate this value by sending their children to the streets early in life to beg for alms. Different cultural and home value systems influences, have produced a variety of patterns of values in the contemporary society. Every culture initiates her young ones to their way of life and occupation and the values attached to occupations are introduced to the child at the crib. For instance, the Fulani teaches 
their children the values of following the cattle about the streets.

Naturally the home is the core base of every human being. The home lays the foundation in the individual child's life. The home is the primary agent of socialization in which the child had his/her first relationship. The family gives the basic knowledge, as well as character, social virtues, values, norms, traditions, customs and mores. The innate psychological factors built in the home act as reservoir from where the growing child draws his/her strength. Every home has its own individuality and peculiar ways life and these individual home variables, value systems and differences grossly influence child rearing practices.

The home value system is a very important item in child's life and personality building because home value system is a reflection of the societal, cultural values and norms which the developing child has to abide by. It takes precedence for the efficient learning and proper personality development of the child. A child is born in a home where he/she remains in the constant company of his/her parents, siblings and members of the extended family during the formative year of the infancy periods. It is evident that it is the home which is in the strategic position to inculcate the cultural habits in the children through child-rearing practices, since they are in full control of them during infancy. The home assures the child security, wanted and loved, by providing the child with his/her legitimate needs and rights.

The home provides conducive environment for balance mental development and builds confidence into the children through rearing practices. Orhungur (1990) observe that any meaningful discussion of a child's growth and development and the influences that shape these, cannot fail to recognize the importance of the home. The importance of the home as the primary agent of socialization has been acknowledged by most authorities of education today. This is because, when school performance is addressed, it does not involve the academic performance and excellence only, but includes moral, social, spiritual, physical, emotional, psychological, economic, political and all attitudinal and behavioural patterns the child has acquired through child rearing practices at home. The home is a reservoir of strength from which children draw to meet their physical and emotional needs, its warm and intimate contacts, contribute to their feeling of security and belonging. The home has certain primary functions which include; socializing the children and to help the children lay proper foundations for developing their potentials and realizing their aspirations. The home assists the children in learning their different cultural values. Children are reared in a way that reflects the personality of their parents, behavioural patterns and value orientations of their culture. The home provides a conducive and healthy environment, rich in developmental skillful experiences as part of cultural value system, where the child is allowed to interact and participate. The home encourages the child to extend the interaction to the outside environment-the school. This may be the reason people from different cultural backgrounds can positively interact with others, (Nwoke, 1997).

However, Nweze (1996) observe that with more women taking to professional careers and paid employment outside the home, the direct consequences are enormous in value of child-rearing practices. In Nigeria as in other parts of the world, situation have been created whereby mothers and fathers are becoming absentee parents as they are being forced by the de- mands of their jobs and professions to spend less time at home with their children. It is observed that parental absenteeism is giving rise to the growing wave of children's maladaptive and delinquent in many urban homes-families across the world. Nweze, (1996, Igbo \& Anugwom, 2011) observed that the conflict generated by the clash between modern and traditional home values have given rise to home crises that lead to increase in divorce and separation among urban couples. Nwoke (2007) observed that the issues of divorce and separation have led to single parenthood, step parenthood and step children hood syndromes. These forms of home system tend to generate more home conflicts and coalitions and affect the emotional and social well being of children. Modern home value systems seem to contravene the observed traditional home value system. Uzoka, (2010) observed that the contravention of value systems creates unhealthy living in some families, division, strife and rancor, even separation or divorce.

The purpose of this study was to investigate the influence of cultural value system and the home on child-rearing practices in the contemporary Nigerian society. Also to examine whether modernity has any influence on cultural value system and childrearing practices in the contemporary Nigerian society. It is hoped that this study will shed light on how value systems are inculcated to generations of offspring through child-rearing practices in the home.

\section{Method}

The study was purely qualitative, involving direct observation, interview, dialogue, discussion and interaction with the participants.

Participants: These were sixteen adult men and women $(8$ men, 8 women) from four ethnic groups in Nigeria, the Igbo, Ogoni, Tiv and the Yala. Age (56 - 74) years, with a mean age of 65 years from each group freely participated in the study.

Instrument: A semi-structured questionnaire was used to elicit responses from participants:

1) Cultural value systems are inculcated to generations of offspring through child-rearing practices. Can you tell me how you transmit cultural values to generations of your offspring?

2) Has the home any influence in transmitting cultural value system in child-rearing practices?

3) Has modernity influenced cultural value system and home on child-rearing practices in the contemporary Nigeria society?

Procedure: In the course of this study the researcher came in contact with the participants, held interview and discussion with the sixteen adults in groups of four ( 2 men, 2 women) according to ethnic group, concerning their cultural value systems and how such are passed on to generations of the people.

Design/Statistic: Qualitative technique, using semi-structured forms of data collection, both interviewing and discussion were employed. This study was purely descriptive.

\section{Results}

Results were based on the summarized responses from the participants.

Research Question 1: Cultural value systems are inculcated to generations of offspring through child-rearing practices. Can you tell me how you transmit your cultural values to your offspring?

The participants' responses were: 
Nigeria is a country with multiple ethnic groups, cultural backgrounds and diversified value systems. Each group has her peculiar way of inculcating the values prevalent in her tribe to generations of offspring. For example the breaking of kola nut in Igboland, the Tiv and their excessive possession of land and cultural attire, the Ogoni and their yaa and koo initiation rites and Yala and her Queen-dancing and salt baking. These and other numerous cultural values like cooking and eating pattern, mode of farming and rearing of animals, greeting styles and dress code, gender roles, sitting pattern, songs, are transmitted to the members from these groups through child-rearing practices in the home.

Research Question 2: Has the home any influence in transmitting cultural value in child-rearing practices?

The participants' responses were:

The home is a type of nursery bed for nurturing cultural value system. It is the most important agent of socialization, promoting all forms of values, giving direction, informal education; chains of good moral behaviours, habits of healthy personality development and later adjustment are rooted in the home. Unquestionably the home lays the foundation of every good human being who respects his/her cultural values through child-rearing. The home is a miniature society and custodian of all cultural values. The home provides the first human interaction through child-rearing. Through child-rearing practice what a boy or a girl should do or not do is inculcated to the child.

- Among the Igbos females do not climb palm tree or tap palm wine, females do not fell iroko tree and kola nut is not shown to females when in a gathering or in a function no matter the age of the female.

- In Tivland females do not drive away millipede from the house. It is the believe that women do not own the house and therefore do not have the authority to do so.

- In Tiv land, females do not make mounds in the farm; they only weed the farm and gather fruits.

- Among the Ogoni, females make pots of all types and males build canoes. Ogoni attach much importance to yaa and koo initiation rites for both genders.

- Among the Yala males wrestle and engage in acrobatic displays while the females do queen-dancing and bake salt. These cultural values are inculcated to generations of offspring through child-rearing practices in the home. The home is the encyclopedia that explains cultural value systems through child-rearing.

Research Question 3: Has modernity influenced cultural value system and home on childrearing practices in the contemporary Nigerian society?

The participants' responses were:

Modernity has affected child-rearing practices. All the respondents cited example with the type of wears people put on and all the mannerisms. In the contemporary time males plait their hairs, put on earring and dress like females. Also females go in trousers like males. The issue of female circumcision is grossly affected as some cultures have dropped this value, while some adherents hold it tight. Of course female circumcision has become the hot debate of modern society. Work family role, vividly conflict in the modern time on child-rearing value system. Children are left under the care of a mother surrogate type in the day-care from critical tender age and most of the home values which the child should have internalized in the home become strange or foreign to the child.

\section{Discussion}

Based on the findings of current this study, Nigeria as a multicultural nation with diversified cultural value systems has different ways of transmitting their values to her generations of offspring through child-rearing practices in the various ethnic groups. Cultural value system of greeting, methods of cooking different types of food, clothing, dancing, songs, folklore, magic and all cultural properties for which a group is known are inculcated to generations of the members of the group through child-rearing practices. To understand the cognitive and social development of children, this study revealed that it is better to examine the social and the cultural processes shaping children. The findings of the present study seem to support all the literature reviewed which strongly attested that cultural value systems are transmitted to generations of offspring through child-rearing practices. The present study revealed that the pattern of farming or pattern of rearing animals, are transmitted during child-rearing at the age of five years. The findings of present study support Nwoke, (2004) who discovered that many tribes in Nigeria introduce their children to their various occupations at the age of five years, even though the child may not be able to do the work meant for the adult. $\mathrm{He} / \mathrm{she}$ is conditioned to the line of thought and behaviour of his/her gender in that culture.

To understand the influence of the home, based on the general findings of this present study, all the respondents affirmed that the home serves as a nursery bed where cultural value systems are nurtured, incubated and disseminated. According to the present findings, the home is the primary agent of socialization that promotes all forms of values that give the developing human being a sense of guide and direction. The present study revealed that the home lays the foundation on which every good or bad pattern of behaviour is built. The findings of this current study showed that whatever the lifestyle of the home, such is inculcated to the child through rearing practices. The findings of the present study also showed that the home is a miniature society and custodian of all societal values, from where the growing child draws his/her strength. The current findings showed that the home is a type of moral mirror from where the child views his/her attitudes and activities. The present findings buttress Nwoke, (1997) who observed that factors in the home or direct teaching by parents through child rearing have great influence on the child. The findings of this study revealed that through child-rearing practices, each ethnic group transmits to the boy or girl child what he/she should do or not do, as well as culturally defined sitting patterns for males and females.

Among the Igbos, the present study revealed that the females do not climb palm tree or tap palm wine, females do not fell iroko tree. Also it was discovered in this study that kola nut is not shown to females when in a gathering or in a function no matter the age. The current findings revealed that if kola nut was to be given to a female because of her social status, she does not pick the kola nut from the dish by herself, it is picked by a male who then gives it to her. The present findings indicated that females carry out domestic chores and prepare the type of food for which the culture is known. The present findings also showed that in Igbo culture females sit with legs closed. From the findings it is disclosed that males climb all types of trees, tap palm wine, fell trees, rear animals and do other male related duties in the home. These cultural values are inculcated to generations of Igbo human beings through child- 
rearing practices.

About the Tiv people, the findings of this study showed that in Tivland, females do not drive away millipede from the house because it is believed that the female is not the owner of the house. The findings of this present study indicated that in the farm females do not make mounds, they only weed the farm and gather fruits. The current findings disclosed that Tiv females take care of the children, keep the house and prepare all types of Tiv food. This study revealed that the Tiv people have common unique attire which differentiates them from other ethnic group in Nigeria. The current finding also disclose that Tiv farm land is termed "sacred" and any form of encroachments attracts war, and that is the reason Tiv always fights against land dispute with neighbours. All these cultural values are transmitted to generations of Tiv children through childrearing practices in the home.

Concerning the Ogoni, the present study revealed that females make pots and males build canoes. The findings of this current study showed that the Ogoni people hold high their "yaa" and "koo" initiation rites for both males and females. The present finding supports Nwideeduh, (1998), who observe that an Ogoni man is ready to spend a treasure in the "yaa" and "koo" initiation of his children than to invest a kobo in their education. These values and other salient ones are inculcated to Ogoni generations through child-rearing practices in the home. The findings of this present study showed that Yala males wrestle and engage in acrobatic displays for entertainment, while the females do the queen dancing with the intricate steps of a queen. Also the women engage in salt baking while men rear animals and farm. The values are transmitted to generations of Yala people through childrearing practices in the home.

Understanding the influence of modernity on cultural value system, all the respondents of this present study unanimously attested that modernity has affected child-rearing practices. The participants cited example with the type of wears people put on in the contemporary Nigerian society and all the mannerism. These findings affirmed that the issue of female circumcision is another value that has been grossly affected as some cultures have dropped this value, while some adherents hold it tight. These findings showed that people's lifestyles and paid job employment have also affected child-rearing in the home, as children at such critical period of development are deprived of the parental nurturing they deserved. This finding buttresses, Nweze, (1996; Nwoke, 2007; Aluko, 2009) who observed that work family role conflict in the modern society has some negative influence on child-rearing value system. Children are left under the care of people who may be foreign to their cultural value systems, thereby strange values may be transmitted to the children through interaction with the caregiver.

\section{Conclusion}

This study showed that cultural value system is embedded in the culture of the people. The findings indicated that the home serves as a nursery where the cultural value systems are nurtured and disseminated to generations of human beings through child- rearing practices. The present study revealed that modernity has influenced value systems and child-rearing practices in the contemporary Nigerian society because of work family role conflict. In addition the current study revealed that some cultural values like female circumcision have become the hot seat for modern debate as what is its value to humanity. However culture is not static it is dynamic, therefore any conflicting issue has to be reconciled with reason.

\section{REFERENCES}

Aluko, Y. A. (2009). Work family conflict and coping strategies adopted by woman in academia. IfepsycholoIaIA: Gender and Behaviour, 7, 2095-2122.

Argyle, M. (1990). Psychology and social problems. London: Butter \& Tanner Ltd.

Berger, K. S., \& Thompson, R. A. (1998). The developing person through the life span. New York: Worth Publishers.

Bohannan, P. (1965). The Tiv of Nigeria. In J. L. Gibbs (Ed.), People of Africa. New York: Halt Rinehart and Winston.

Cherlin, A. (1992). Marriage, divorce, remarriage. Social trends in the US. Cambridge, MA: Harvard University Press.

Chukwuagguh, C. C. (1998). Culture and its development through time. The African indigenous experience. Afe: Journal of Minorities Studies, 2, 92-97.

Dacey, J. S., \& Travers, J. F. (2002). Human development across life span. New York: McGraw-Hill.

Downess, R. M. (1933). The Tiv tribe. Kaduna: Michigan Baker-House

Dukor, M. (2010). African philosophy in the global village theistic pompsychic rationality, axiology and science. USA: Lap Lambert Academic Publishing GMBH \& Co. KG.

Evans-Pritchard, E. E. (1940). The nuer. Oxford: The Clarendon Press.

Haralambos, M., \& Heald, R. (1980). Sociology themes \& perspectives. Great Britain: Richarch Clay.

Herskovits, M. J. (1955). Cultural anthropology. New York: Alfred, A. Knopr. Inc. Ltd.

Hurlock, E. B. (1978). Child development. Tokoyo: Kosaido Publishing Co. Ltd.

Igbo, E. U. M., \& Anugwom, E. E. (2011). Social change and social problems. A Nigerian perspective. Nigeria: AP Express Publishing Company Nsukka.

Jov, E. T. (2001). Christian marriage a problem the Tiv experience. Makurdi: Onaivi Printing \& publishing Co. Ltd.

Levine, R. A. (1980). A cross-cultural perspective on parenting. In M. D. Fantini, \& R. Cardenas (Eds.), Parenting in a multicultural society. New York: Longman.

Levine, R. A. (1989). Cultural influences on child development. In W. Douman (Ed.), Child development today and tomorrow. San Francisco: Jossey-Bass.

Nweze, A. A. (1996). The Nigerian family. Impact on adolescent social and emotional adaptation presented at the International Society for the study of behavioural development. Africa Regional Workshop, Lusaka, 18-22 April 1996, 15-22.

Nwideeduh, S. B. (1998). Cultural differentiation and education disparity in Nigeria. The case study of Ogoni. Afe: Journal of Minorities Studies, 2, 7-18.

Nwoke, M. B. (1997). The Influence of the home on children's school performance. Abuja: Niger Grafikes Garki.

Nwoke, M. B. (2004). The effects of ethnic group, age and gender on the bio-socio-cognitive adjustment of teenagers. Unpublished Ph.D. Thesis, Nsukka: University of Nigeria.

Nwoke, M. B. (2007). Impact of home type, age and gender on the antisocial behaviour of secondary school students. Gender \& Behaviour, Ife Center for Psychological studies. International Journal of Psychology in Africa, Ife Psychologia, 5, 1248-1259.

Orhungur, M. M. (1990). Educational trinity, home, child, school. Jos: Nigeria Fab Publications Books.

Phinney, J. S., \& Alipura, L. L. (1990). Ethnic identity in college students from four ethnic groups. Journal of Adolescence, 13, 171-183. doi:10.1016/0140-1971(90)90006-S

Santrock, J. W. (2006). Life-span developmental Psychology. New York: McGraw Hill Companies, Inc.

Sechrest, L., \& Wallace, J. (1967). Psychology and human problems. Columbus, OH: Charles E. Merrill Publishers. 


\section{B. NWOKE}

Uzoka, A. F. (2010). The psychologist as healer: Confronting the dilemma of ethical decay in Nigeria. In P. O. Ebigbo, M. O. Ezenwa, B. C. Agoha, \& J. E. Eze (Eds.), Value system and the health of a nation.
Nigeria: Immaculate publications Ltd. Ogui New Layout Enugu. Wegh, S. F. (1994). Marriage, family and the church in Tiv. Makurdi: Dekon computers services. 